Vol. 39(1), pp. 1-12, June 2020

ISSN 1821-536X (print)

ISSN 2619-8789 (electronic)
Tanzania Journal of Engineering and Technology

Copyright (c) 2020 College of Engineering and

Technology, University of Dar es Salaam

Full Length Research Paper

\title{
Performance Analysis of Renewable Energy Resources in Rural Areas: A Case Study of Solar Energy
}

\author{
Jackson J. Justo* and Aviti T. Mushi \\ Department of Electrical Engineering, University of Dar es Salaam, Tanzania. \\ ${ }^{*}$ Corresponding author: jackjusto2009@gmail.com
}

\begin{abstract}
This paper presents an overview of the recent development trends of solar photovoltaic $(P V)$ systems and the performance in the Tanzanian context. The two types of solar power generation that are considered in this paper are: i) solar PV systems and ii) concentrated solar power (CSP). The two are compared in terms of cost of energy and energy storage mechanism. Moreover, the effect of ambient temperature on the solar PV module is analyzed. In addition, a detailed analysis on using solar axis tracking to increase the power generation is also presented. The extent to which the cell surface temperature and orientation of the solar module which determine the power generation is modeled. Since Tanzania has the possibility to utilize the solar irradiance in the Coastal region to generate solar power, and therefore it is selected as the case study in this paper.
\end{abstract}

Keywords: Concentrated solar power, Levelized cost of electricity, Solar photovoltaic system.

\section{INTRODUCTION}

Recently, a continuous sharp growth is observed in the global solar photovoltaic (PV) renewable energy sector, especially in the year 2017, which saw a phenomenal global PV power generation representing almost $55 \%$ of renewable power generation (Al-Shetwi et al., 2019). Currently, $65 \%$ of grid generation capacity of Tanzania is from thermal and 35\% from large hydropower (African Development Bank Group, 2015), but there is a strong potential for solar energy contributing $24.7 \%$ electrification (Bishoge et al., 2018). Thus, there is an opportunity to consider the effect of adding solar power generation to increase the target set out by the government in the "Electricity for all" programme. The sun can be used for its heating potential as is the case for Concentrated Solar Power (CSP) systems or the photon energy within the light beams can be harnessed with photovoltaic (PV) systems (Busse and Dinter, 2016). Each system has its merits and can be compared against each other using the Levelized Cost of Energy (LCOE) (Esram and Chapman, 2007). Photovoltaic generation depends on factors such as the choice of photovoltaic material and cloud cover, but for this study the focus was the effect of ambient and module temperature as well as the mitigation of the power loss due to module temperature by using single axis tracking. PV technology is still an expensive technology to implement in households and there is a concern related 
to the power quality effects that are caused by the inverters of solar PV systems (Kasa et al., 2016). The control of harmonics is better suited to utilities and not the individual customer households which may be of a lower income (Alexander, 2016). Therefore, a comprehensive review of the factors that affect the implementation of solar power generation scheme are presented hereunder.

\section{Concentrated Solar Power (CSP)}

Concentrated Solar Power (CSP) systems are used to capture and concentrate heat from the sun into heating a fluid that will be used to generate energy. Like most renewable energy systems, there is a need to store the generated energy to be used when the energy source, which is the heat from the sunlight in this case, is not available. For CSP systems, the heat energy can be stored in liquid salt (Busse and Dinter, 2016). Based on the research conducted by Grobbelaar et al. (2014), it was found that it will eventually be the case such that CSP technology will be able to overtake traditional power generation systems. The current factor that contributes to the delay in large scale CSP implementations is the cost of implementation, and low maturity of the technology (Camerada et al., 2015).

\section{Solar Photovoltaic}

Solar photovoltaic systems utilize the energy of the photons in the sunlight to generate DC power, which can be fed to the grid through a simple inverter. Solar panels can be mounted in a fixed position or set up to track the position of the sun via single or dual axis tracking (Solanki, 2015). Typical insolation levels found in Southern Africa region ranges from 4 to 7 $\mathrm{kWh} / \mathrm{m}^{2} /$ day (Baurzan and Jenkins, 2016). The existing energy mix found in Tanzania is eclipsed by natural gas at $45 \%$, followed by hydropower at $42 \%$, fossil fuel account for $12 \%$, and others (Ministry of Energy and Minerals of Tanzania, 2017). Renewable energy features very small percentage in that mentioned mix. However, there are plans to increase the share of renewable energy, by placing a larger emphasis on solar PV ahead of CSP (Ministry of Energy and Minerals of Tanzania, 2017). Tanzania has the greatest potential for solar energy due to its high solar irradiance (Aly et al., 2017). This is an exceptional amount of energy available for the country to utilize and Bahrami et al. (2016) showed that solar tracking increases the energy gained from the sun by $17.7 \%$ to $31.2 \%$. Furthermore, it is argued that a superior performance of PV system is obtained when integrated to DC grid (Adly and Strunz, 2019).

Interfacing PV systems to the grid requires use of inverters, which deteriorates the power quality thus results to injecting harmonics into the grid. Poor power quality is reported to cause significant losses amounting to $\$ 120$ billion/year in the United States of America (Durisch et al., 2000). The strategies used to improve power quality are high frequency switching, which again comes with the burden of increasing switching losses (Tran et al., 2016). Stetz et al. (2013) outlined five possible solutions to improve the power quality when using PV systems. These are as follows: (i) limitation of active power feed to $70 \%$ of the peak power at standard test conditions (STC); (ii) static reactive power provision to control the power factor; (iii) automatic voltage limitation by dynamic active power control; (iv) automatic voltage limitation by both dynamic and reactive power control; and (v) installation of distribution transformers with On-Load Tap Changers.

\section{Energy Storage}

There are various types of systems that can be used for energy storage as shown in Figure 1 where there is a comparison of 
the technologies in operation globally. Batteries are the most widely used technology, followed by pumped storage, and thermal storage.

In accordance with Anake and Wang (2015), battery storage technology is a more mature technology and it can therefore be considered reliable and more readily available. Research regarding batteries is ongoing as the number of devices that require batteries is increasing as well as the power requirement of these batteries. In a household there are laptops, cellular phones and tablets that will all require batteries to be operated and this is the reason for the strong development of battery technology. PV technology is still an expensive technology to implement in households and there is a concern related to the power quality effects that are caused by the power converters like solar chargers and inverters of solar PV systems (Kasa et al., 2016). The control of harmonics is better suited to utilities and not the individual customer households which may be of a lower income (Alexander, 2016).

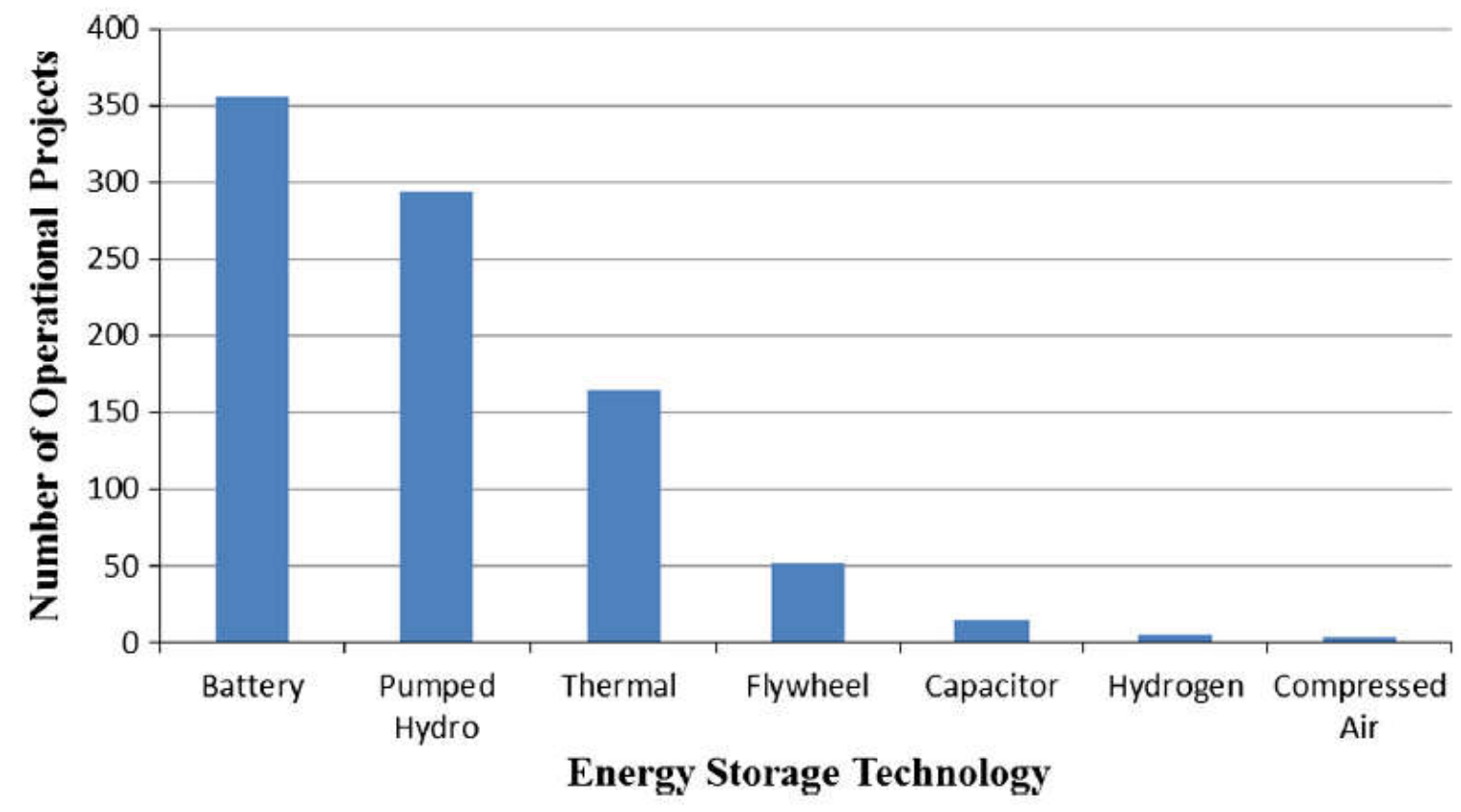

Figure 1: Energy storage technologies across the globe (Anake and Wang, 2015)

\section{DEVELOPMENT OF A MODEL}

This study has used the weather (insolation), of Kisiju Pwani in Tanzania. Data was obtained from the Tanzania Weather Services and used them in the simulations. The model of solar energy calculations was developed and used in the simulations, to calculate the power drop due to temperature variations. Further, solar tracking was implemented and the declination angle was varied for every hour. The levelized cost of energy was used to compare the economy of solar PV against the CSP and wind.

\section{Cell Shading}

The performance of a solar cell can be affected by cloud cover (Kern et al., 1987). As a cloud passes over an area, the solar irradiance transitions from full exposure to fully shaded whilst passing through various levels of exposure in-between. The effects of partial cloud cover have been shown to generate overcurrent conditions when by-pass diodes are used in an overlapping configuration as there is an alternative path provided for current to flow (Ziar et al., 2014). When overlapped cells are partially shaded there will be a shift in the maximum power point that will 
cause a low voltage but high current (Villa et al., 2012). Figure 2 shows cells $C_{l}$, $C_{2}, \ldots, C_{6}$ connected in series, with overlapping diodes $D_{1}$ and $D_{2}$. These cells produce respective currents $I_{i},(\mathrm{i}=1,2, \ldots$, 6) when illuminated. When cell $C_{3}$ is partially shaded, its current becomes zero. Therefore, the currents from cells $C_{1}$ and $C_{2}$ will flow through the overlapping diode $D_{2}$. However, the cloud cover effect will not be considered in this paper due to the complication introduced by adding a cloud cover model into the calculations.

The effect of temperature on a solar cell has also been investigated by Kern et al. (1987), and it was shown that due to the application of direct sunlight onto the PV cell, there is an associated increase of temperature on the surface of the cell, which causes a reduction in the power output. It was confirmed that silicon solar cells can experience a decrease of $0.5 \%$ in power output for every degree Celsius increase in temperature of the PV cell surface. The temperature of the PV cell can be calculated as per equation (1).

$T_{\text {cell }}=T_{\text {amb }}+\frac{\left(N_{O C T}+20^{\circ}\right)}{0.8} \times S$

Where $T_{\text {cell }}$ is the temperature of the cell surface in degree Celsius, $T_{a m b}$ is the ambient temperature in the vicinity of the cell, $N_{O C T}$ is the nominal operating cell temperature, and $S$ is the solar irradiation. The choice of laminate on the solar cell will also have an effect on the efficiency of the PV cell. The selection of a good glass can result in an increased efficiency over a non-laminated PV cell as the glass can assist in reducing the reflection losses. The laminate choice will not be considered in the calculations due to added complexity in calculations introduced by this factor.

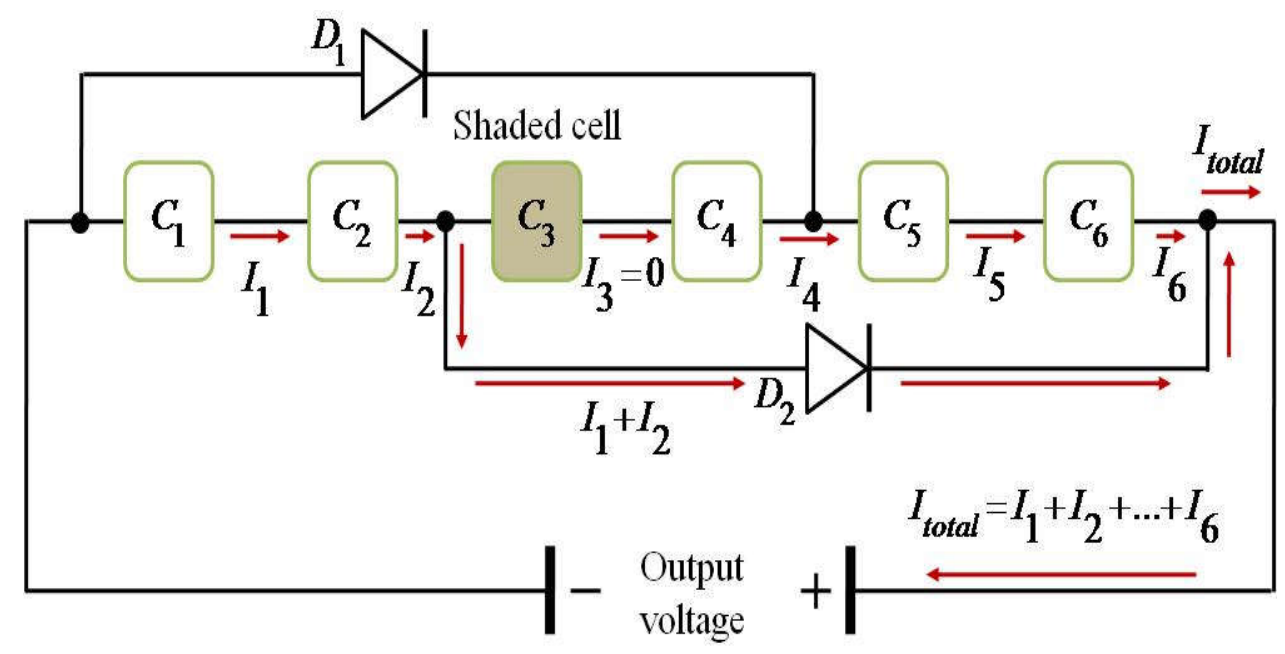

Figure 2: The overlapping diode configuration shows that when $\mathrm{PV}$ cell $C_{3}$ is in a shade and its current is zero, the overlapping diode $D_{2}$ provides an alternative path for current to flow (Ziar et al., 2014)

\section{Solar Energy Calculations}

The energy available from the sun to the collector will come from three insolation sources: direct beam insolation; diffuse beam insolation; and reflected beam insolation, which comes from the nearby surfaces that reflect light onto the collector. Equations (2) through (7) were used to describe the insolation beams of importance (Solanki, 2015):

$$
\begin{aligned}
& I_{B}=A e^{-k m} \\
& A=1160+75 \sin \left[\frac{360}{365}(n-275)\right]
\end{aligned}
$$




$$
\begin{aligned}
& k=0.174+0.035 \sin \left[\frac{360}{365}(n-100)\right] \ldots \\
& m=\frac{1}{\sin \beta} \quad \ldots \ldots \ldots \ldots \ldots \ldots \ldots \ldots \ldots \\
& \sin \beta=\cos L \cos H-\sin L \sin \delta \ldots \ldots \ldots \\
& \delta=\frac{1}{\sin \beta} 23.45 \sin \left[\frac{360}{365}(n-81)\right] \ldots \ldots
\end{aligned}
$$

Where: $I_{B}$ is the direct beam portion at the earth's surface in $\mathrm{W} / \mathrm{m}^{2} ; A$ is the apparent extra-terrestrial flux; $k$ is the optical depth; $\mathrm{n}$ is the day number in the year, where 1 is January $1^{\mathrm{st}} ; \mathrm{m}$ is the air mass ratio; $\beta$ is the altitude angle; $L$ is the latitude of the site in degrees; $H$ is the hour angle, where $0^{\circ}$ for midday, -ve for PM, +ve for AM and $15^{\circ}$ change for each hour; and $\delta$ is the solar declination angle.

Although there are six equations to be processed in order to calculate the beam insolation at the surface of the earth, there is only a requirement to have three variables, namely: the day of the year, the time of that day, and the latitude of the site. Using $I_{B}$ it is then possible to calculate the insolation striking a surface based on the direct, diffuse and reflected beams in the vicinity of the solar panel collector. To calculate the direct beam radiation, equations (8) through (10) are used. To use these equations, the tilt and azimuth angle of the collector must be known as additional information.

$I_{B C}=I_{B} \cos \vartheta$

$\cos \theta=\cos \beta \cos \left(\phi_{s}-\phi_{c}\right) \sin \sum+\sin \beta \cos \sum$

$\sin \phi_{s}=\frac{\cos \sigma \sin H}{\cos \beta}$

Where: $I_{B C}$ is the direct beam radiation on the collector; $\theta$ is the angle of incidence on the surface of the collector; $\phi_{\mathrm{s}}$ is the azimuth angle of the sun; $\phi_{\mathrm{c}}$ is the azimuth angle of the collector; and $\Sigma$ is the tilt angle of the collector.
The diffuse radiation calculations are defined by equations (11) and (12). To calculate these values, there are no additional variables to include beyond what is already in equations (3) to (10).

$$
\begin{aligned}
& I_{D C}=C x I_{B}\left(\frac{1+\cos \sum}{2}\right) \ldots \ldots \ldots \ldots \ldots \ldots \ldots \\
& C=0.095+0.04 \sin \left[\frac{360}{365}(n-100)\right] \ldots .
\end{aligned}
$$

Where $I_{D C}$ is the diffuse radiation in $\mathrm{W} / \mathrm{m}^{2}$, and $\mathrm{C}$ is the approximate sky diffuse factor. The final component to consider is the reflected radiation that comes off the nearby surfaces onto the surface of the collector in accordance with equation (13).

$$
I_{R C}=\rho \times I_{B}(\sin \beta+C)\left(\frac{1-\cos \Sigma}{2}\right) \ldots
$$

where: $\mathrm{I}_{\mathrm{RC}}$ is the reflected radiation in $\mathrm{W} / \mathrm{m}^{2}$, and $\rho$ is the reflectance of the surface.

\section{Variation in Power due to Temperature}

Analysis of effects of temperature on solar $\mathrm{PV}$ generation is done based on equations (2) through (13) and some assumptions for the dataset. Tanzania's highest solar levels are observed in the Coastal Region which is a dry and hot place as noted by the recorded temperature data provided by the Tanzanian Weather Services (2015). The solar PV model used in this paper, will calculate the solar radiation at the point of a collector including the direct, diffuse and reflected radiation components. The temperature at the surface of the PV module is given by equation (1), and the effect of the PV module surface temperature was calculated as a $0.5 \%$ drop in power for every ${ }^{\circ} \mathrm{C}$ above $25^{\circ} \mathrm{C}$, which is described by equation (14), where $P$ is the actual power incident on the cell, $P_{\text {Tcell }}$ is the power output from the cell at $T_{\text {cell }}$ temperature. The two graphs will be compared to show the drop-in power available for the PV module to utilize. 


$$
P_{\text {Tcell }}=P\left[1-0.005\left(T_{\text {cell }}-25\right]\right.
$$

The assumptions made for the model are summarized in Table 1 . There are only six hours of useful sunlight, which means that the hour angle varies between $+45^{\circ}$ to $-45^{\circ}$ in a day's calculations. The tilt of the collector is set to $0^{\circ}$ which makes it parallel to the surface of the Earth. A subsequent result of this is that the reflected radiation on the collector will always be zero. This is mathematically confirmed by equation (13) where inserting a zero into the equation will always result in $\cos \left(0^{\circ}\right)$ producing a 1 which will cause the equation to equate to zero.

Table 1: Assumptions for the Model Variables

\begin{tabular}{|c|l|l|}
\hline No. & Variable & Assumption \\
\hline 1 & Hour angle & There is only sunlight from between 9 a.m. and 3 p.m. \\
\hline 2 & Tilt & $0^{\circ}$ \\
\hline 3 & Area of collectors & $10 \mathrm{~m}^{2}$ \\
\hline 4 & Tracking & There is no solar tracking \\
\hline 5 & NOCT & $47^{\circ} \mathrm{C}$ \\
\hline 6 & Site Latitude & $-28.409893^{\circ}$ \\
\hline 7 & Collector Azimuth & $180^{\circ}$ (Facing North) \\
\hline
\end{tabular}

\section{Levelized Cost of Energy for PV}

The Levelized Cost of Energy (LCOE) is a technique used to compare technology costs, including the operating and maintenance costs, with amount of energy produced. The equation for the LCOE is given in the following (Baurzan and Jenkins, 2016).

$$
L C O E=\frac{\sum_{t=1}^{n} \frac{I_{t}+F O C_{t}+V O C_{t}}{(1+r)^{t}}}{\sum_{t=1}^{n} \frac{E_{t}}{(1+r)^{t}}} \ldots \ldots \ldots
$$

where in year $\mathrm{t}, I_{t}$ is the investment expenditure, $F O C_{t}$ is the fixed operating expenditure, $V O C_{t}$ is the variable operating cost, $E_{t}$ is the energy produced in $\mathrm{kWh}, r$ is the discount rate, and $n$ is the operational lifetime of equipment in years.

\section{RESULTS AND DISCUSSION}

The results of the calculations using the assumptions in Table 1 are displayed in Figure 3. The purpose of the graph is to trend the behaviour of the data based on the inputs. Specific considerations are listed in Table 2 for further discussion.

Data shown in Figure 3 begins from $1^{\text {st }}$ January 2015 and ends on $31^{\text {st }}$ December 2015. It was shown that there is a drop in the available power during the rainy seasons, but also that the colder climate yields a smaller gap between the available power and the powers after the temperature effects are considered. This implies that the solar cells are more efficient during rainy periods. However, the positive effect of this efficiency during the rainy months is offset by the lower overall power available during those months.

On average, the drop-in power due to temperature is approximately $18.1 \%$. The largest drop in power is $25.7 \%$ which occurs on the 7 th day of the year during the hours between 2 p.m. and 3 p.m. where the ambient temperature was at its highest in the year at $42^{\circ} \mathrm{C}$. The lowest drop in 
power was $7.9 \%$, which occurred on day 211 when the ambient temperature is $7^{\circ} \mathrm{C}$.

Table 2: Values for consideration

\begin{tabular}{|l|l|l|l|l|}
\hline & $\begin{array}{l}\text { Power } \\
(\mathrm{W})\end{array}$ & $\begin{array}{l}\text { Ambient } \\
\text { Temp } \\
\left({ }^{\circ} \mathrm{C}\right)\end{array}$ & $\begin{array}{l}\text { Cell } \\
\text { Temp } \\
\left({ }^{\circ} \mathrm{C}\right)\end{array}$ & $\begin{array}{l}\text { Power } \\
\text { after temp } \\
\text { loss }(\mathrm{W})\end{array}$ \\
\hline Average & 7624 & 27 & 61 & 6194 \\
\hline Minimum & 3243 & 7 & 40 & 2706 \\
\hline Maximum & 11287 & 42 & 76 & 9507 \\
\hline
\end{tabular}

The drop in overall power can be attributed to the reduced solar radiation in the rainy months as the solar declination becomes more positive. The shape of the graph in Figure 4 to that of the power graphs in Figure 3, shows the inverse relationship that exists between the power available and the solar declination. In Tanzania, the negative solar angle that occurs in the dry months will produce more direct sunlight beams on the surface of the collector and hence the increased power availability. Therefore, the change in solar declination causes a drop in power available at the collector, but since this change in solar angle also corresponds to colder climate conditions, it can be said that the effect of power loss due to the positive solar declination is reduced by the colder climate as shown in Figure 3 as the gap between the 2 graphs is smallest during the coldest rainy months.

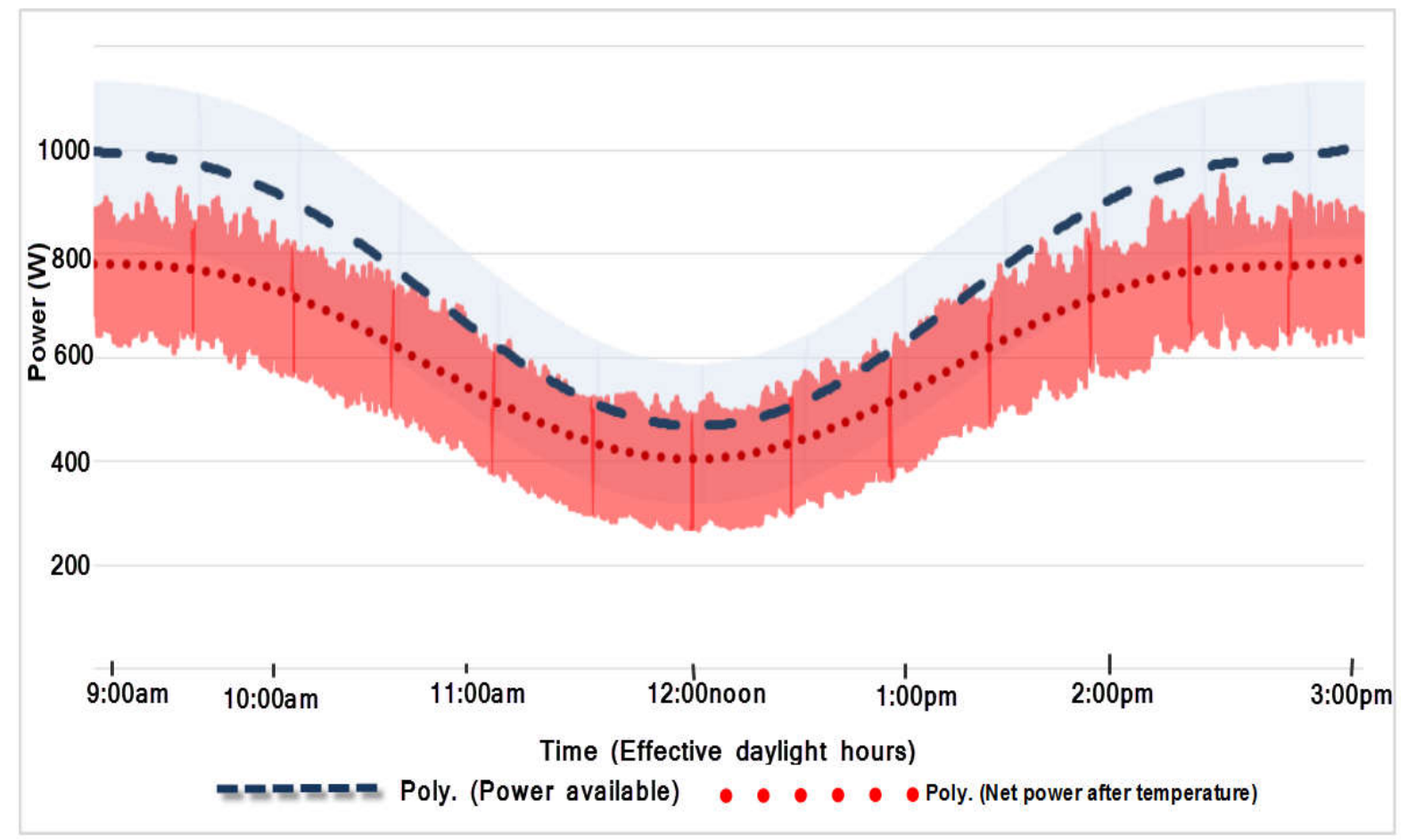

Figure 3: The comparison of the power available with and without consideration for the temperature 


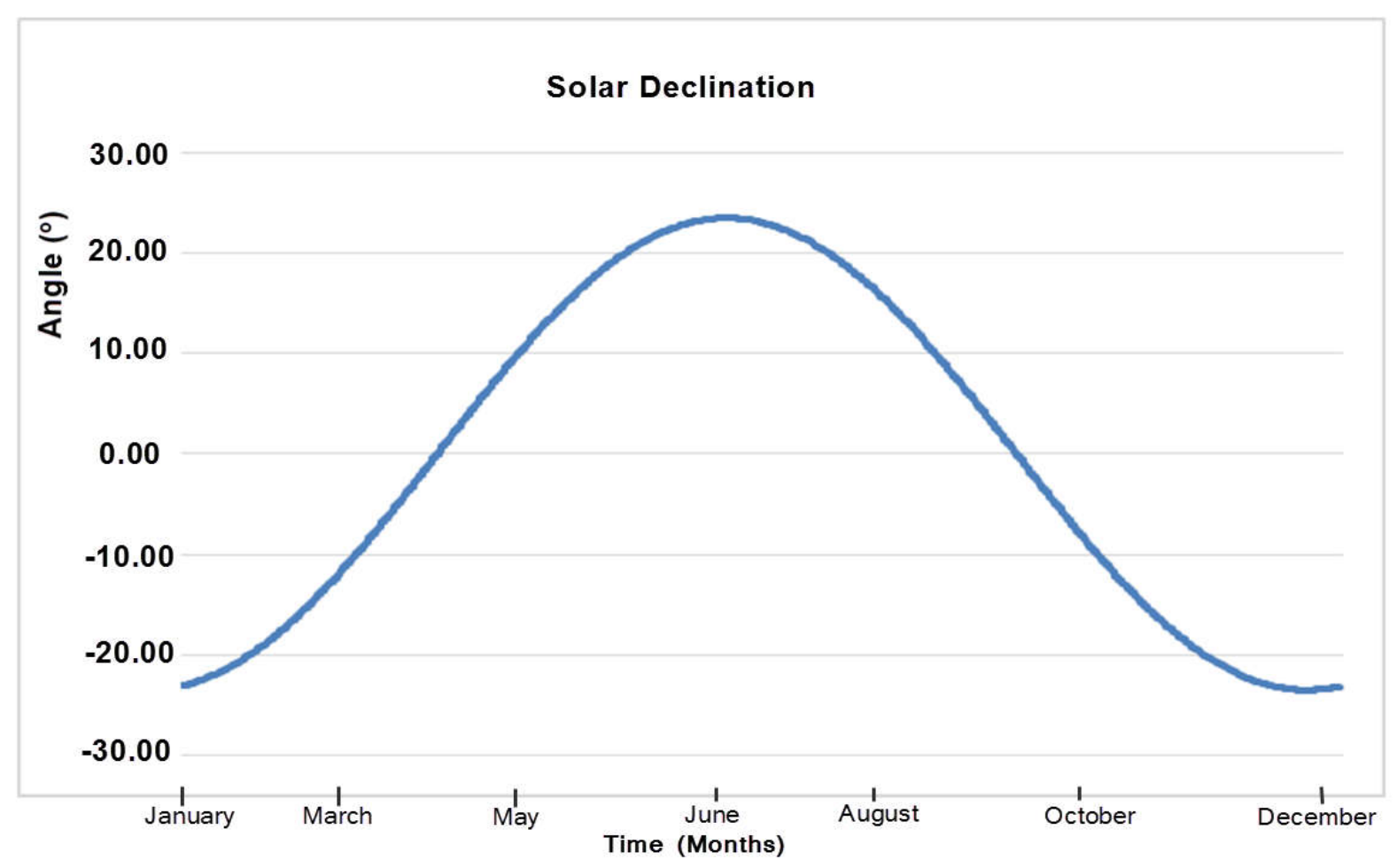

Figure 4: The solar declination angle of the sun for a year starting in January and ending in December, when compared to the shape of Figure 3 it shows an inverse relationship

\section{Implementing Solar Tracking}

To test the effect of solar tracking, the model parameters were changed for months from the start of April (day 90) to end of September (day 272) where the tilt was changed to a fixed $45^{\circ}$ and the collector azimuth was set to change by $15^{\circ}$ every hour between 9 a.m. and 3 p.m. starting at $90^{\circ}$ at 9 a.m. and changing to $0^{\circ}$ as summarized in Table 3.

Table 3: Solar Tracking Configuration

\begin{tabular}{|c|c|}
\hline Angle Hour (Degrees) & $\begin{array}{c}\text { Azimuth of Collector } \\
\text { (Degrees) }\end{array}$ \\
\hline 45 & 90 \\
\hline 30 & 75 \\
\hline 15 & 60 \\
\hline 0 & 45 \\
\hline-15 & 30 \\
\hline-30 & 15 \\
\hline-45 & 0 \\
\hline
\end{tabular}

The results of these changes are shown in Figure 5, which shows a less defined dip in shape which indicates a smaller drop in power for both the available power and the power after considering temperature. It is worth to note that during the colder months, the gap between the graphs is still there and just like Figure 3, the gap between the graphs is smallest during the coldest months. It was also observed that there is the additional reflected radiation component that can add some extra power since there is a tilt to the collector. This is shown to be in the region of between 19 and $35 \mathrm{~W}$.

Table 4 shows the values for consideration, this time with solar tracking being implemented for 6 months of the year. The maximum values have not changed at all as these occur in the dry season, but the minimum values have now increased by $41 \%$ from $3243 \mathrm{~W}$ to $5498 \mathrm{~W}$ 
of available power striking the surface collector. The overall increase in minimum power after taking into account the effect of temperature is approximately $41 \%$. A substantial increase in power can be realised by implementing a simple single axis tracking system set at $45^{\circ}$ and rotating at this tilt.
Table 4: Values for Consideration

\begin{tabular}{|l|c|c|c|c|}
\hline & $\begin{array}{l}\text { Power } \\
(\mathrm{W})\end{array}$ & $\begin{array}{l}\text { Ambient } \\
\text { Temp } \\
\left({ }^{\circ} \mathrm{C}\right)\end{array}$ & $\begin{array}{l}\text { Cell } \\
\text { Temp } \\
(\mathrm{oC})\end{array}$ & $\begin{array}{l}\text { Power } \\
\text { after temp } \\
\text { loss }(\mathrm{W})\end{array}$ \\
\hline Average & 8510 & 27 & 61 & 6945 \\
\hline Minimum & 5498 & 7 & 40 & 4623 \\
\hline Maximum & 11287 & 42 & 76 & 9507 \\
\hline
\end{tabular}

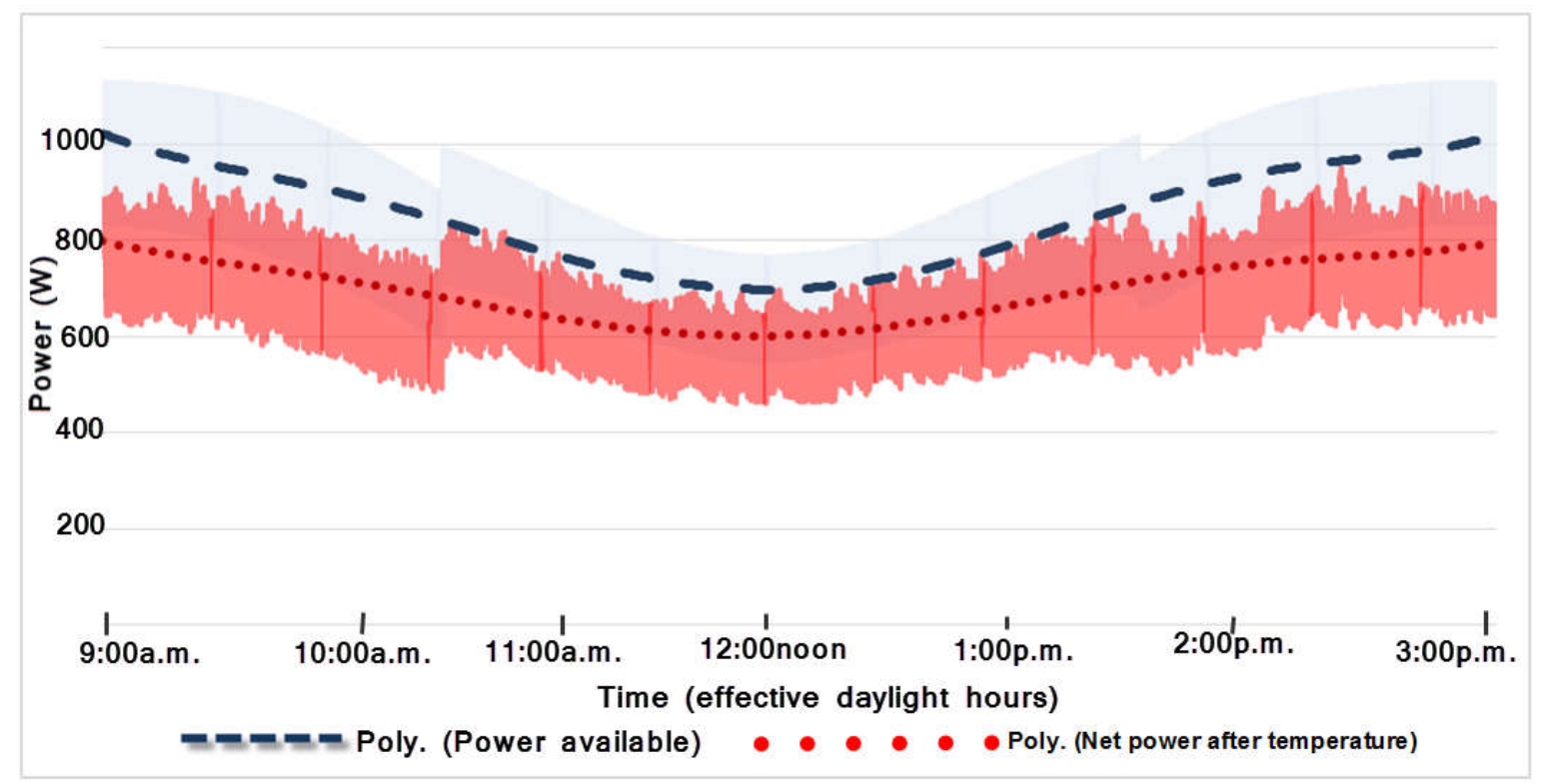

Figure 5: The effect of tracking during the colder months showing a less pronounced dip in the graphs

\section{Comparing the Costs of CSP against PV}

Equation (15) was used by Landry and Gagnog (2015) to compare various energy generation costs and the results are summarized in Table 5. The study shows that there is a benefit of using CSP when it comes to the cost. The cost of the solar PV system varies greatly depending on the choice of batteries as well as axis tracking system used. The cost of solar PV will affect the implementation as a distributed generation (DG) technology as noted by Baurzan and Jenkins (2016). Solar PV may still be an attractive solution for utility power generation instead of DG implementations as the lower income consumers in Tanzania cannot afford to invest in the stand-alone solar PV system.
Table 5: LCOE For Generation Technologies

\begin{tabular}{|l|c|}
\hline Technology & LCOE $\mathbf{( \$ / y r ) ~}$ \\
\hline Solar PV & $0.16-0.63$ \\
\hline CSP & $0.13-0.36$ \\
\hline Wind (on shore) & $0.04-0.09$ \\
\hline
\end{tabular}

When comparing the use of CSP and PV, it was observed that both CSP and PV require that the energy generated must be stored as thermal or electrical energy, respectively. Within the Tanzanian context, there is a greater emphasis on the planned implementation of PV systems as opposed to CSP systems. The LCOE is the quantity that can be used to compare the financial benefit of using a particular technology. Such a comparison is useful as it includes hidden costs including 
operations and maintenance, and it was shown that CSP has a benefit over PV when comparing the LCOE. When comparing the energy storage technologies across the world, it was seen that electrical energy storage via chemical batteries is the most mature technology based on the number of active implementations across the world. This is a major benefit for PV systems over CSP as it shows there is security and safety in using the required energy storage of $\mathrm{PV}$ systems as the technology is mature. PV technology is still an expensive technology to implement in households and there is a concern related to the power quality affects that are caused by the inverters of solar PV systems (Kasa et al., 2016). The control of harmonics is better suited to utilities and not the individual customer households which may be of a lower income (Alexander, 2016).

\section{CONCLUSIONS}

When comparing the use of CSP and PV, it is found that both CSP and PV require that the energy generated must be stored as thermal or electrical energy respectively. Within the Tanzanian context, there is a greater emphasis on the planned implementation of PV systems as opposed to CSP systems. In terms of LCOE comparison which is useful as it includes hidden costs including operations and maintenance, it is shown that CSP has a benefit over PV. When comparing the energy storage technologies across the world, it was seen that electrical energy storage via chemical batteries is the most mature technology based on the number of active implementations across the world. This is a major benefit for PV systems over CSP as it shows that there is security and safety in using the required energy storage.

The effect of temperature on the power output for PV module has been tested by using a mathematical model made in
Microsoft Excel. It was observed that the power available decreases with ambient temperature and that the power available also decreases during the rainy months due to the solar declination. The effect of temperature is such that there is approximately $25 \%$ drop in the dry months and approximately $8 \%$ drop in available power in the rainy months. Single axis solar tracking implemented to compensate for the solar declination during the rainy months was found to increase the power generated by the PV system.

Based on the conclusions above, it is recommended that solar PV systems only be considered for utility generation and not stand-alone DG energy plans as the cost of such implementation would be far too significant for the lower income users. Since Tanzanian sunlight radiation is good throughout the country, which is not as densely populated as other regions, it is better for the utility to harness the energy of the sun and transmit this power via a transmission network to the regions of the country that require the power. This utility will have the required resources including finance and technical skills to better overcome the harmonic and power quality issues associated with solar PV generation. Solar axis tracking produces a more consistent level of power but also raises the cost, which will prevent it from being used by the lower income households in the most effective manner. Therefore, it is a further economic justification for the utility to generate the power in bulk and not the individual household.

\section{REFERENCES}

Adly M. and Strunz K. (2019). Efficient Digital Control for MPP Tracking and Output Voltage Regulation of Partially Shaded PV Modules in DC Bus and DC Microgrid Systems. IEEE Transactions on Power Electronics, 34(7): 63096319. DOI: 10.1109/TPEL.2018.2873753 
African Development Bank Group (2015). Renewable Energy in Africa: Tanzania Country Profile. Available online at https://www.afdb.org/fileadmin/uploads /afdb/Documents/Generic-

Documents/Renewable Energy in_Afri ca - Tanzania.pdf. Accessed on $2^{\text {nd }}$ November 2019.

Alexander A. (2016). Development of Solar Photovoltaic Inverter with Reduced Harmonic Distortions Suitable for Indian Sub-Continent. Renewable and Sustainable Energy Reviews, 56(1): 694-704.

https://doi.org/10.1016/j.rser.2015.11.092

Aly A., Jensen S.S. and Pedersen A.B. (2017). Solar Power Potential of Tanzania: Identifying CSP and PV Hotspots through a GIS Multicriteria Decision Making Analysis. Renewable Energy, 113: 159 - 175, https://doi.org/10.1016/j.renene.2017.05 .077

Al-Shetwi A.Q., Sujod M.Z., Blaabjerg F. and Yang Y. (2019). Fault RideThrough Control of Grid-Connected Photovoltaic Power Plants: A Review. Solar Energy, 180: 340-350. DOI: 10.1016/j.solener.2019.01.032

Anake M. and Wang M. (2016). Energy Storage Technologies and Real-Life Applications - A State of the Art Review. Applied Energy, 179(1): 350377.

DOI:

10.1016/j.apenergy.2016.06.097

Bahrami A., Okoye C. and Atikol U. (2016). The Effect of Latitude on the Performance of Different Solar Trackers in Europe and Africa. Applied Energy, 177(1): 896-906. DOI: 10.1016/j.apenergy.2016.05.103

Baurzan S. and Jenkins G. (2016). OffGrid Solar PV: Is it an Affordable or Appropriate Solution for Rural Electrification in Sub-Saharan African Countries. Renewable and Sustainable Energy Reviews, 60(1): 1405-1418. https://doi.org/10.1016/j.rser.2016.03.016
Bishoge O.K., Zhang L. and Mushi W.G. (2018). The Potential Renewable Energy for Sustainable Development in Tanzania: A Review. Clean Technology, $\quad 1$ : 70-88. https://doi.org/10.3390/cleantechnol101 0006

Busse K. and Dinter F. (2016). Overview of Predictive CSP Spread Prospects and its Opportunities. Journal of Energy in Southern Africa, 27(2): 50-60. DOI: https://doi.org/10.17159/24133051/2016/v27i2a1341

Camerada M., Cau G., Cocco D., Damiano, A., Demontis V., Melis T. and Musio M. (2014). A Pilot Power Plant Based on Concentrating Solar and Energy Storage Technologies for Improving Electricity. 69th Conference of the Italian Thermal Engineering Association, ATI2014. DOI: 10.1016/j.egypro.2015.12.071

Durisch W., Tille D., Wörz A. and Plapp W. (2000). Characterisation of Photovoltaic Generators. Applied Energy, 65(1): 273-284. RePEc:eee:appene:v:65:y:2000:i:14:p:273-284

Esram T. and Chapman P. (2007). Comparison of Photovoltaic Array Maximum Power Point Tracking Techniques. IEEE Transactions on Energy Conversion, 22(2): 439-449. DOI: 10.1109/TEC.2006.874230

Grobbelaar S., Gauche P. and Brent A. (2014). Developing a Competitive Concentrating Solar Power Industry in Tanzania: Current Gaps and Recommended Next Steps. Development Southern Africa, 31(3): 475-493.

DOI: 10.1080/0376835X.2014.891971

Kasa S., Ramanathan P., Ramasammy S. and Kothari D. (2016). Effective Grid Interfaced Renewable Sources with Power Quality Improvement Using Dynamic Active Power Filter. International Journal of Electrical 
Power and Energy Systems, 82(1): 150160. DOI: $10.1016 /$ j.ijepes.2016.03.002

Kern E. Gulachenski E. and Kern G. (1987). Cloud Effects on Distribution Photovoltaic Generation-Slow Transients at the Gardener, Massachusetts Photovoltaic Experiment. IEEE Transactions on Energy Conservation, 4(2): 184-190. DOI: $10.1109 / 60.17910$

Landry M. and Gagnog Y. (2015). Energy Storage: Technology, Applications and Policy Options. International Conference on Alternative Energy in Developing Countries and Emerging Economies. Edmundson.

Solanki C.S. (2015). Solar Photovoltaics: Fundamentals, Technologies and Applications. Third Edition, Delhi: PHI Learning.

Stetz T., Marten F. and Braum M. (2013). Improved Low Voltage GridIntegration of Photovoltaic Systems in Germany. IEEE Transactions on Sustainable Energy, 4(2): 534-542. DOI: 10.1109/TSTE.2012.2198925

Ministry of Energy and Minerals of Tanzania. (2017). Tanzania Power System Master Plan. Available online at http://open_jicareport.jica.go.jp/pdf/122 88619.pdf. Accessed on $2^{\text {nd }}$ November 2019.

Tanzanian Weather Services (2015). Kisiju Temperature Data 2015.

Tran Q-T., Truong A.V. and Phuong M.L. (2016). Reduction of Harmonics in Grid-Connected Inverters Using Variable Switching Frequency. International Journal of Electrical Power and Energy Systems, 82(1): 242251.

https://doi.org/10.1016/j.ijepes.2016.03. 027

Villa L.P.L., Picault D., Raison B., Bacha S. and Labonne A. (2012). Maximizing the Power Output of Partially Shaded Photovoltaic Plants Through Optimization of the Interconnections Among its Modules. IEEE Journal of Photovoltaics, 2(2): 154-163. DOI: 10.1109/JPHOTOV.2012.2185040

Ziar H., Nouri M., Asaei B. and Farhangi S. (2014). Analysis of Overcurrent Occurrence in Photovoltaic Modules with Overlapped by-pass Diodes at Partial Shading. IEEE Journal of Photovoltaics, 4(2): 713-721. DOI: 10.1109/JPHOTOV.2013.2292578 